\title{
Using a Structural Retirement Model to Simulate the Effect of Changes to the OASDI and Medicare Programs
}

\author{
Timothy Waidmann \\ Urban Institute \\ John Bound \\ University of Michigan and NBER \\ Todd Stinebrickner \\ University of Western Ontario
Prepared for the Sixth Annual Conference of Retirement Research Consortium
"The Future of Social Security"
August 12-13, 2004
Washington, DC

\begin{abstract}
Acknowledgements: Financial support was provided by the National Institute on Aging (R01 AG17579-01), the Robert Wood Johnson through the Economic Research Initiative on the Uninsured at the University of Michigan, and the Social Security Administration through the Michigan Retirement Research Center. Michael Stevens provided able research assistance. The project was made computationally feasible by our access to the supercomputer resources of SHARCNET at the University of Western Ontario, which were developed with funding from the Canadian Foundation for Innovation and the Ontario Research and Development Challenge Fund. We would like to thank system administrator Gary Molenkamp and Baolai Ge for their help on the computing front. Stinebrickner has also benefited from a time-release supported under the SHARCNET fellowship program. We have benefited from the comments on an earlier version of this paper from seminar participants at the University of Michigan and the Canadian Econometric Study Group and especially Chris Swann, Steve Haider, and Paul Contoyannis.
\end{abstract}

The research reported herein was performed pursuant to a grant from the U.S. Social Security Administration. The opinions and conclusions are solely those of the author and should not be construed as representing the opinions or policy of the Social Security Administration or any agency of the Federal Government or the Retirement Research Consortium. 


\section{Introduction}

With an aging population on the one hand and difficulties in financing public and private pensions on the other, understanding the determinants of individuals' retirement behavior is of considerable research and policy importance. Much of the research on the labor force behavior of older, working aged adults has focused on the effects of financial incentives such as Social Security and private pensions, generally showing that these incentives have powerful behavioral effects. At the same time, econometric studies of retirement behavior have provided strong evidence for the importance of health factors

Unfortunately, efforts to understand the effects of financial incentives on retirement behavior and understand the effects of health on retirement behavior have remained largely separate avenues of research. There exist strong empirical correlations among health, socioeconomic status, and the rewards from continuing to work. Behaviorally, health status and economic factors interact in their effects on labor force behavior. For example, people in poor health will presumably continue to work unless they have the resources to permit them to stop, while those are who not able to stop working may adapt to their poor health in other ways, for instance by changing jobs. As a result, economic factors confound the effects of health on retirement, and vice versa.

In this paper we hope to improve understanding of the labor force behavior of older Americans by specifying and estimating a model of labor force behavior that builds on the strengths and addresses some of the weaknesses of the two largely separate literatures. The benefits of drawing on valuable lessons learned in each are readily apparent. On one hand, research examining the relationship between financial resources and retirement decisions has established the importance of viewing retirement as a dynamic process which can best be viewed longitudinally. Acknowledging this basic idea seems necessary if one wishes to fully understand the relationship between health and retirement. Although variation in mental health, cognitive functioning, and physical health exists at all ages and affects early educational and occupational attainment, it is the decline in physical and mental health starting in late middle age - often in combination with a changing occupational environment - that is likely to create a mismatch between an individual's capabilities and the requirements of his job. Whether and how workers respond to declines in health depends on various factors, including the nature of the declines, their expected persistence, the age at which they occur, and workers' human capital, economic situation, and preferences for leisure and consumption. Research on the effect of health on retirement has virtually ignored these dynamic issues.

On the other hand, research examining the relationship between health and retirement has stressed the importance of carefully dealing with issues related to the measurement of health with a specific focus on the potential problems 
associated with using global survey measures such as self-rated work limitations and global self-rated health. There are a number of potential problems with such survey measures, particularly relating to measurement error and endogeneity. First, respondents are asked for subjective judgements which may not be entirely comparable across individuals. Second, responses may not be independent of the very labor market outcomes investigators hope to explain. Third, since health may represent one of the few legitimate reasons for working-age adults to be out of work, respondents out of the labor force may mention health problems to rationalize their behavior. Fourth, since early retirement benefits are often available only for those deemed incapable of work, respondents may have a financial incentive to identify themselves as disabled, an incentive that will be particularly high for those for whom the relative rewards from continued work are low. It is important to note that each of these problems will lead to different kinds of biases (Bound, 1991) and biased estimates of health's impact on outcomes will also lead to biased coefficients on any variable correlated with health. ${ }^{1}$ Unfortunately, these issues have largely been ignored in most past longitudinal retirement research which has suffered from the availability of only very limited measures of health. ${ }^{2}$

${ }^{1}$ Evidence to date on the nature of the biases involved in using global self reported health measures (e.g.. responses to questions such as "Do you have any impairment or health problem that limits the kind or amount of paid work you can do?" or "Would you say your health is excellent, very good, good, fair or poor?" as are asked in the HRS) in behavioral models is mixed. Stern (1989) and Bound (1991), using instrumental variable procedures to deal with the potential endogeneity of global self reported health measures, found evidence that global measures neither dramatically over or under-estimated the effect of health on labor force participation in reduced form cross sectional models of labor force participation. Bound, Schoenbaum, Stinebrickner and Waidmann (1998) obtain similar results using longitudinal data from the Health and Retirement Study. Bound (1991) and Bound et al. (1998) interpret this result as suggesting that the endogeneity and errors-in-variables bias's approximately cancel each other out. However, even if this is the case, biases may remain in the estimated effects of any variables that are correlated with health. Kreider (1999) produces evidence suggesting that the use of global self-reported measures will tend to yield results that underestimate the impact of financial incentives on labor force behavior. The modeling strategy we follow in this paper allows for both random and systematic components to any measurement error in self reported health.

${ }^{2}$ In a recent paper Benitez-Silva, Buchinsky, Chan, Cheidvasser and Rust (2000) argue that, at least when studying the decision to apply for Social Security Disability Insurance, self reported measures of work incapacity (i.e. responses to the questions: "Do you have any impairment or health problem that limits the kind or amount of paid work you can do? If so, does this limitation prevent you from working altogether?") provide unbiased measures of work capacity. This finding is at odds with the common presumption in the literature, at odds with the evidence that, both across countries and across time within the U.S., the fraction of individuals reporting themselves unable to work mirrors the fraction of individuals receiving disability insurance (Waidmann, Bound and Schoenbaum, 1995; Bound and Waidmann, 2002; Burkhauser, Dwyer, Lindeboom, Theeuwes, Woittiez, 1999), and at odds with results reported in Bound et al. (1998). In particular, in this latter paper, strategies similar to some of those used by Benitez-Silva et al. indicate that, while a dichotomous measure based on the question "Do you have any impairment or health problem that limits the kind or amount of paid work you can do?" produces estimates that neither dramatically over or underestimate the impact of work limitations on retirement, a dichotomous measure that is coded 1 if the person identifies himself as unable to work and 0 otherwise (this is the same kind of measure as is used by Benitez-Silva et al.) tends to dramatically exaggerate the impact of work limitations on retirement. We suspect that the most important reason for the differences between the Bound et al. and the Benitez-Silva et al. findings has to do with differences between the exclusion restrictions used by the two sets of authors. In particular, Benitez-Silva et al. use a much sparser list of exclusion restrictions than do Bound et al. As a result, one concern is that the Benitez-Silva et al. tests may have low power. 
The importance of dynamic considerations motivates our use of a dynamic, discrete choice model. This framework has been found to be useful in previous longitudinal studies of retirement such as Berkovec and Stern (1991) and Rust and Phelan (1997). However, within this general framework we embed a statistical model of health that has been used in the health literature and allows us to deal explicitly with the problems of endogeneity and measurement error that may arise from the use of global measures of self-reported health.

\section{Data}

The estimation of the specified model requires a rich data source. We take advantage of the Health and Retirement Study (HRS) which, in an effort to allow researchers to address the types of research questions posed here, biennially surveys a sample of Americans who were aged 50 to 61 when the initial survey wave was collected in 1992 . The estimation of our model uses the public release versions of the first four waves of data, supplemented by confidential matched data from the Social Security Administration giving earnings histories and from employers giving details of private pension plans in which respondents are enrolled. The HRS is described in additional detail in Juster and Suzman (1995).

Accurate information on all potential financial sources that could influence the retirement decision is important since, for reasons alluded to earlier, incomplete information about economic resources will tend to lead to biased estimates of the effects of both other financial variables and health on labor force participation. Finally, the HRS contains detailed information about a person's activity state in a particular year. While some individuals who encounter poor health may have the economic resources to simply leave the workforce, other individuals with insufficient economic resources may find that qualifying for Disability Insurance benefits represents the only plausible way to leave the workforce. Still others may try to adapt to their health status by finding a new job. While fully understanding the relationship between financial resources, health, and labor force participation would seem to require that one consider the variety of ways individuals adapt to poor health, to date very little research has attempted to model the effect of health on labor force transitions other than retirement.

We restrict our attention to single men to avoid complications associated with joint decision making, and because single women's Social Security benefits are more likely to depend on the earnings of former spouses-information that is unavailable to us. The age-eligible wave 1 sample consists of 733 single/unpartnered men. From this group, we exclude respondents who did not have a SS earnings history (206), who were not eligible for SS retirement or DI benefits at baseline (153), who claim to have a private pension on their current job with no matching employer record (31), or who have missing values on required data elements(15). These exclusions left 328 respondents who were included in the initial conditions sample. Of these, 132 were not employed (or were self employed) at the date of their wave 1 interview. The remaining 196 respondents make up the "behavioral sample." 


\section{Model Specification and Solution}

We model the behavior of males who are working as of a "baseline" time $\mathrm{t}=0$ which we assume corresponds to the first wave (1992) wave of the Health and Retirement Study. The basic behavioral model is a dynamic programming model in which individuals take into account that current period decisions may have substantial effects on their future utility. Central to this model is a set of current period utility equations that allows a person to construct the expected lifetime utility or value that he will receive from each option that he considers in each year that he makes a decision.

The solution of the value functions and the estimation of the parameters of these "behavioral" equations is complicated by our desire to address two issues. First, the group of individuals who are working at our baseline time period is a group of individuals selected on unobservable factors. Second, although our model posits that individuals make decisions based on actual health, as mentioned earlier, it is self-reported health that is observed in our data.

We attempt to address the former concern by adding a reduced form initial conditions equation that describes whether a person is working at our time period. We address the latter concern in a manner proposed by Bound (1991) by adding a latent health equation that formally describes the relationship between self-reported health, health reporting error, and true health. The presence of these additional equations has several practical implications that increase the difficulty of the solution and estimation of our model. First, in order for the additional equations to serve their purpose, our estimation procedure must allow correlations between certain unobservables that appear in the initial conditions equation, the health equation, and the behavioral equations, making closed-form solutions to likelihood and value functions impossible.

Second, our health framework produces a continuous measure of true health that is serially correlated over time, a wellknown challenge for researchers employing dynamic, discrete choice estimation methods.

We first briefly outline the model used.

Choice Set: Each individual has a finite decision horizon beginning at $\mathrm{t}=1$ (1993) and ending at year $\mathrm{t}=\mathrm{T} .^{3}$ At each time $\mathrm{t}$, an individual chooses an activity state from a finite set of mutually exclusive alternatives, $\mathrm{D}_{\mathrm{t}} \subset\{\mathbf{C}$ areer job, $\mathbf{B}$ ridge job, Not working, Apply for DI\}, governed by the following rules: 1)Once leaving a career job, one cannot return to it; 2) DI application can occur until NRA, if DI application successful, no further work occurs, and benefits continue until death; 3) No return to any job if one stops working after age 70 .

Income: $\mathrm{Y}^{\mathrm{j}}(\mathrm{t})$ is the sum, under choice $j$, of income from wages, Social Security, DB \& DC pensions, DI, nonpension wealth, food stamps, SSI, and other exogenous sources of income (such as veteran benefits) minus expenditures on

${ }^{3}$ In practice, we assume that $\mathrm{T}$ is the year that the person turns 75 years old. After year $\mathrm{T}$, individuals are assumed to remain out of the workforce for the remainder of their lives. 
health care. This approach to modeling the effect of the availability health insurance is now common in the literature (Rust and Phelan, 1997; Blau and Gilleskie, 2001; French and Jones, 2000). Career job (real) wages are assumed to evolve over time following a fixed effects specification. Bridge job wages depend on age and career job wages. Health expenditures depend on health, age and insurance status. Consistent with much previous research in the dynamic, discrete choice literature we assume that a person consumes all of his "income" in year t. ${ }^{4}$

Utility: The current period reward in any year $t$ for choice $j$ contains all of the benefits and costs associated with $j$ and is the (weighted) sum of the utility from consumption (CRRA), and non-pecuniary utility.

We assume that the nonpecuniary utility associated with an option $\mathrm{j}$ is a linear function of a person's current health $\eta_{\mathrm{t}}$, an indicator of whether the person has either private health insurance or Medicare, exogenous observable characteristics of the individual $\mathrm{X}(\mathrm{t})$, and a set of other transitory factors $\left(\epsilon_{\mathrm{t}}^{\mathrm{j}}\right)$ unobserved by the econometrician (but known to the individual in the current period) that measure the person's particular circumstances and outlook in year $t$. In addition, we allow individuals to have unobserved, permanent differences in their preferences for work by including a person-specific, permanent heterogeneity term $\kappa$ that enters the non-pecuniary utility associated with the work options $\mathrm{C}$ and $\mathrm{B}$. To summarize,

$$
\begin{aligned}
& \mathrm{R}^{\mathrm{j}}(\mathrm{t})=\mathrm{U}_{\text {cons }}^{\mathrm{j}}(\mathrm{t})+\mathrm{U}_{\mathrm{np}}^{\mathrm{j}}(\mathrm{t})=\tau \frac{\mathrm{Y}^{\mathrm{j}}(\mathrm{t})^{1-\theta}}{1-\theta}+\lambda_{\mathrm{X}}^{\mathrm{j}} \mathrm{X}(\mathrm{t})+\lambda_{\mathrm{HI}} \mathrm{HI}{ }^{\mathrm{j}}(\mathrm{t})+\kappa 1(\mathrm{j}=\mathrm{Cor} \mathrm{B})+\lambda_{\eta}^{\mathrm{j}} \eta_{\mathrm{t}}+\epsilon_{\mathrm{t}}^{\mathrm{j}}, \quad \mathrm{j}=\mathrm{C}, \mathrm{B}, \mathrm{N}, \mathrm{A} . \\
& \text { Discounted Expected Utility }- \text { Value Functions: } \quad \text { Letting } \mathrm{S}(\mathrm{t}) \text { represent the set of all state variables at time } \mathrm{t} \text {, }
\end{aligned}
$$

the expected present value of lifetime rewards associated with any option that is available at time $t$ can be represented by a standard Bellman equation (Bellman 1957):

$\mathrm{V}_{\mathrm{j}}(\mathrm{t}, \mathrm{S}(\mathrm{t}))=\mathrm{R}^{\mathrm{j}}(\mathrm{S}(\mathrm{t}))+\beta(\mathrm{S}(\mathrm{t})) \cdot \mathrm{E}[\mathrm{V}(\mathrm{t}+1, \mathrm{~S}(\mathrm{t}+1)) \mid \mathrm{S}(\mathrm{t}), \mathrm{j}(\mathrm{t})]$ where $\mathrm{V}(\mathrm{t}+1, \mathrm{~S}(\mathrm{t}+1))=\max \left\{\mathrm{V}_{\mathrm{k}}(\mathrm{t}+1, \mathrm{~S}(\mathrm{t}+1))\right\}$

$\beta$ is the one period discount factor which varies across people and across time depending on individual's survival probabilities. $\beta=\beta^{\text {Common }} \cdot \operatorname{Pr}($ Alive at $\mathrm{t}+1 \mid$ Alive at $\mathrm{t})$. Probabilities depend on age and health at $\mathrm{t}$, estimated with a discretetime proportional hazard model using SSA life tables for baseline hazards.

Health: A person's health, $\eta$, is exogenously determined but correlated across time. We assume that health at time $\mathrm{t}$ depends on demographic characteristics in $\mathrm{X}(\mathrm{t})$, as well as specific health measures $\mathrm{Z}(\mathrm{t})$, and follows an AR(1) process.

\footnotetext{
${ }^{4}$ In recent work researchers have begun to introduce savings into dynamic programing models of retirement (e.g . French, 2000a,b; van der Klaauw and Wolpin, 2002; Rust, Buchinsky and Benitez-Silva, 2001). Doing so requires treating savings as a continuous state variable and consumption as a continuous choice variable which significantly complicates estimation. In all these cases the authors have treated health as an exogenous discrete state variable. In contrast, we treat health as a continuous state variable and allow for the potential endogenous reporting of health status, but ignore savings. While adding savings as a state variable and consumption as a choice variable is possible from a conceptual standpoint, in practice this change in our specification would render our already complicated model intractable. Given our interest in the the interplay among health, financial resources, and the labor market behavior, we believe our choice was a reasonable one.
} 
Health Insurance: Individual beliefs about health insurance status at time $t+1$ is determined by his age (i.e., Medicare eligibility), health insurance characteristics of his current job and the choice made at $t+1$. Career job health insurance may or may not provide retiree coverage, but for computational reasons, we assume that bridge jobs do not have retiree coverage. However, persons in bridge jobs without insurance have some probability $(0.2)$ that the bridge offer he receives in time $\mathrm{t}+1$ will include health insurance. In addition, we allow COBRA insurance at time $\mathrm{t}+1 .{ }^{5}$

Thus, at time $t$, the state variables that influence non-pecuniary utility are $\left\{X(t), \epsilon(t), \kappa, \eta_{t}, H I(t)\right\}$. Except for $\epsilon(t)$ and $\kappa$, these also affect current and future net income levels through their effects on health expenditures. In addition, some new state variables are needed to represent a person's information about income. For example, income calculations depend in part on a set of baseline variables, 6 , that describe everything about a person's financial situation, previous work and earnings history, and earnings potential when the person arrives at $\mathrm{t}=1$. Our model is made tractable through an assumption that an individual considers expected future earnings rather than actual future earnings when thinking about future SS benefits. In this case, sufficient for computing the SS benefits that a person will receive in some future year $\mathrm{t}^{*}$ is the person's earnings history as of time $\mathrm{t}=1$ (which is contained in 6 ), the number of years that he will work in his career job after time zero and before time $t^{*}$, the number of years that he will work in his bridge jobs before time $t^{*}$, and a variable which keeps track of all relevant information about what years the person worked after age 62 and before time $t^{*}$. These three state variables are endogenously determined within the model. ${ }^{6}$

As with the SS calculation, we assume that individuals consider expected future earnings when thinking about pensions and DI payments. DB payments from career job at $t^{*}$ can be calculated if he knows the details of the pension plan and his earnings history as of $\mathrm{t}=1$ (both in 6 ) and the year that he left his career job. ${ }^{7}$ With respect to DC plans, future payments at $t^{*}$ will depend on details of the plan, past contributions, and future contributions(assumed to continue at same rate)and thus depend on 6 and $\mathrm{EXC}(\mathrm{T})$. Potential DI benefits are based on health and the same data required for SS formulas. To summarize, the time $t$ state variables in the model are $S(t)=\{6, X(t), \operatorname{EXC}(t), \operatorname{EXB}(t), \operatorname{SSEX}(t), \operatorname{DI}(t), \epsilon(t)$, $\left.\psi(\mathrm{t}), \mathrm{L}(\mathrm{t}), \kappa, \eta_{\mathrm{t}}, \mathrm{HI}(\mathrm{t})\right\}$.

${ }^{5} \mathrm{We}$ assume that the cost of this coverage is $\$ 1000$.

${ }^{6}$ Essentially, these variables are sufficient to characterize the entire wage history that is relevant for the SS calculation if the person thinks about expected wages in the future.

${ }^{7}$ The year that an individual left his career job is given by the amount of experience that a person had at the end of his decision making horizon, $\mathrm{EXC}(\mathrm{T})$, since individuals cannot return to career jobs after leaving these jobs. 
Solving value functions: The expected value of choice $j$ in $t+1$ is a multi-dimensional integral over the stochastic elements of $\mathrm{S}(\mathrm{t}+1)$ whose realizations are not known at time $\mathrm{t}$ given the decision to choose $\mathrm{j}$. The recursive formulation of value functions motivates the backwards recursion solution process that is standard in finite horizon, dynamic, discrete choice models.

\section{Estimation}

Individuals make choices by comparing the values of the various options that are available. Generally speaking, our estimation approach is to choose parameters that maximize the probability of observed choices. The additional complications are the serially correlated and endogenous nature of health and the selectivity of the initial sample. The strategy we have chosen to deal with the reality that true health is not observed is to use a latent variable model to construct an index of health (Bound 1991, Bound et al. 1999). Essentially, our latent variable model uses the detailed health information available in the HRS to instrument the potentially endogenous and error-ridden work limitation measure. This validity of this approach for estimating the effects of health on labor force withdrawal depends critically on the assumptions that the reports on the detailed health information available in the HRS are exogenous with respect to labor force status.

In an attempt to account for selectivity in the sample we include in our estimation a reduced form initial conditions equation modeled as a probit. Credible identification of the covariance between the initial condition and the behavioral equations depends crucially on exclusion restrictions. In particular, some variable or variables must influence the initial condition, but have no direct effect on subsequent behavior. In our case we have assumed that, while health at $t=0$ affects whether or not one works at $\mathrm{t}=0$, it does not have a direct effect on subsequent behavior after conditioning on health at $\mathrm{t}=1$.

\section{Results}

We are interested in understanding how the availability of economic resources and health affect economic behavior. Tabulations of income sources stratified by work and health status (not shown) suggest that men are not likely to leave the labor force before the age of 62 unless they have income sources on which they can rely, but that the composition of the income sources that are used to support an exit from the labor force varies dramatically with health status.

Recall that the choice data used to identify the behavioral portion of the model come from the activity status of our behavioral sample at approximately yearly intervals. The third through sixth columns of table 4 report descriptive statistics on our behavioral sample broken down by whether they chose $\mathrm{C}, \mathrm{B}, \mathrm{A}$, or $\mathrm{N}$ in the final survey. ${ }^{8}$ There are several things

${ }^{8}$ Persons are classified as having applied for disability benefits are those who apply at any time between the 1992 and 1998 surveys. Persons who have not applied for disability benefits and are still working but who have changed jobs since the baseline survey are classified as "Bridge." Those alive and not working in the final survey who have not applied for disability 
to note. Those who retire (i.e., choose option N) are more likely to be eligible for a private defined benefit pension and more likely to have reached age 62 by wave 4 than those who did not. What is more, those who retire (N)--and especially those that applied for DI benefits (A)--were no more likely to be in poor health or report a work limitation at their wave 1 interview, but were much more likely to report health problems as of the final survey. These patterns make considerable sense.

The average person in our behavioral sample would receive \$12,820 in SS benefits at age 65 (based on the contributions made as of the baseline interview) and would receive DI benefits of the same amount if he is approved for the program. On average, the expected career wages and bridge wages at the final survey based on estimates of equation (5) and equation (6) are $\$ 32,854$ and $\$ 13,098$ respectively. The final row of Table 4 show that the proportion of individuals in the sample who choose the options $\mathrm{C}, \mathrm{B}, \mathrm{N}$, and $\mathrm{A}$ is $.430, .204, .279$, and .087 respectively.

The model we estimate includes the parameters of the DI approval equation, career and bridge wage equations, the health expenditure equation, the health status equation, the utility/choice functions, the initial conditions equation, the standard deviation of unobserved heterogeneity, covariances between health reporting and choice functions, between baseline work (initial condition) and unobserved health, and between baseline work and unobserved work disutility, the common discount factor, and the risk aversion parameter. Estimates of some of these are shown in table 5D. The estimate of $\tau$ indicates that the amount of consumption available from a particular option plays a statistically significant role in the utility that is derived from that option. The estimates also indicate that health plays a statistically significant role. Given that larger values of health represent worse health, the negative estimates of $\lambda_{\eta}^{\mathrm{C}}$ and $\lambda_{\eta}^{\mathrm{B}}$ indicate that individuals in bad health get less utility from the work options (relative to the option $\mathrm{N}$ ) than individuals in better health. The positive estimate of $\lambda_{\eta}^{\mathrm{A}}$ indicates that individuals in bad health get higher non-pecuniary benefits from applying for Disability Insurance (relative to the option $\mathrm{N}$ ) than individuals in better health. Our estimates imply that, over and above the effect of health insurance on disposable income, health insurance has a positive effect on well being, but the estimated effect is quite small and not statistically significant. In terms of the variance/covariance terms, most striking is the importance of unobserved heterogeneity; the point estimate (standard error) of the standard deviation $\sigma_{\mathrm{\kappa}}$ is $1.423(.322)$.

In order to quantify the role that economic resources and health play in determining labor decisions we begin by performing simulations using a "representative person." We construct a representative person who has a college education and has career earnings, bridge earnings, SS benefits, and potential DI benefits that are close to the average for people in our

benefits are classified as "Retired." 
sample, but has no private pension wealth or other sources of wealth. ${ }^{9}$ We first assume that the representative person has true health $\eta_{1}$ at time $\mathrm{t}=1$ that is equal to the average true health of the individuals in our sample. The five rows of Table $6 \mathrm{~A}$ show simulated choice probabilities at $t=1$ assuming that the representative person is $55,60,62,64$, and 65 years of age at $\mathrm{t}=1$ respectively where to simplify the discussion and make tables more readable we have combined the Career and Bridge options into a single "working" category $(\mathrm{C}+\mathrm{B})$. Since the simulated individuals would have been employed at $\mathrm{t}=0$, these simulated probabilities can be thought of as one year transition rates.

The simulated choice probabilities at age 55 and age 60 are quite similar. At these ages, the representative person's only economic resources if he leaves the workforce come from assistance programs such as the food stamp program. This reality, combined with the fact that being in average health implies that it is not particularly unenjoyable to work and that applying for Disability Insurance is not particularly worthwhile, implies that the person at age 55 and age 60 has a very low probability of leaving the workforce for either the non-work option N (0.02) or for the option of applying for Disability Insurance A (0.001). Evidence regarding the effect of economic resources on behavior can be seen by comparing the choice probabilities at the age of 60 to the choice probabilities at the age of 62 at which time the person becomes eligible for Social Security retirement benefits. The consumption increase in the non-work option $(\mathrm{N})$ causes the probability of choosing this option to increase by a factor of approximately two (from 0.024 to 0.046 ). The fact that the probability of applying for DI remains extremely small (0.003) for the average health person even when SS benefits become available is evidence of the very strong importance of health in the DI application decision. ${ }^{10}$ Delaying retirement past the age of 62 increases a person's Social Security benefits. Comparing simulated choice probabilities between the age of 62 and the ages of 64 and 65 reveals that this increase in Social Security benefits has a relatively small effect on retirement decisions.

Table 6B shows choice probabilities at different ages for the representative person under the assumption that his health is one standard deviation below average at $\mathrm{t}=1 .^{11}$ As before, the choice probabilities are fairly similar at ages 55 and

${ }^{9}$ Our representative person would receive $\$ 15,588$ in SS benefits at age 65 (given amount of contributions as of time $\mathrm{t}=1$ ), and would receive DI benefits of $\$ 15,588$ if approved for the program.

0.Before age 62, a person with no outside wealth who applies for DI must rely on social assistance such as food stamps while waiting for the approval decision. However, at age 62 a person can receive SS benefits while waiting for the DI approval decision.

${ }^{11} \mathrm{~A}$ large share of those in poor health as of the initial HRS survey year do not make it into our behavioral sample. Thus, a large share of those in poor health as of $\mathrm{t}=1$, would not have been in poor health two years earlier and would have suffered a major negative health shock in the interim. Thus, while lagged health does not enter the behavioral model, it probably still makes sense to interpret the results in terms of the behavioral effects of the deterioration in health status, rather than the effects of permanently poor health. 
60 for this person. However, comparing the choice probabilities for this person at ages 55 and 60 to the choice probabilities for the average health person at ages 55 and 60 indicates that health has a very important effect on the probability that a person will transition out of the workforce at ages 55 and 60. For example, the total probability of transitioning out of the workforce $(\mathrm{N}+\mathrm{A})$ at age 60 is 0.025 for the average health person and is 0.106 for the below-average health person with the impact of worse health coming from both an increase in the probability of choosing the non-work category (N) and an increase in the probability of applying for DI (A). Comparing these two numbers with the choice probabilities of the average and below-average health individuals at age 62 indicates that the effect of economic resources depends to some extent on health. At age 62 when SS benefits become available, the total probability of transitioning out of the workforce increases by approximately 0.06 (from 0.106 to 0.168 ) for the person in below-average health but increases by only approximately 0.02 (from 0.025 to 0.049 ) for the person in average health.

Table 6C shows choice probabilities at different ages for the representative person under the assumption that his health is 1.5 standard deviations below average. Comparing the results of Table $6 \mathrm{C}$ to those of $6 \mathrm{~B}$ indicates that, once a person reaches poor health, an incremental worsening of health can have large effects on the decisions of individuals. When compared to the representative person in Table $6 \mathrm{~B}$ (who has health 1 standard deviation below average), the representative person in Table 6C is at least twice as likely to apply for Disability Insurance at each age and is approximately .10 more likely to transition out of the workforce $(\mathrm{N}+\mathrm{A})$ at each age. Comparing Table $6 \mathrm{C}$ to Table $6 \mathrm{~A}$ reinforces the notion that the availability of economic resources may influence individuals in poor health more than individuals in good health. At age 62 when SS benefits become available, the total probability of transitioning out of the workforce at $\mathrm{t}=1$ increases by approximately 0.07 (from 0.198 to 0.269 ) for the person in below-average health but, as discussed before, increases by only approximately 0.02 (from 0.025 to 0.049 ) for the person in average health.

Potential Changes in Policy The simulations involving the representative person suggest that changes in policy that influence economic resources may have substantial effects on individual behavior and that these effects may vary across people with different health. Here we use our baseline model and our behavioral sample to simulate the effects of four potential changes in policy. First, we examine the effect of removing the option of early SS benefits. Second, we examine the effects of a policy that has been implemented - changing the normal retirement age from 65 to 67 . Third, we examine the impact of removing the Disability Insurance program entirely. Finally, we examine the impact of implementing a type of universal health insurance program. 
To quantify the effects of these policy changes, we first perform a baseline simulation in which no policy change has occurred. This simulation yields the probability that each person in our behavioral sample will choose each of the options $\{\mathrm{C}, \mathrm{B}, \mathrm{N}, \mathrm{A}\}$ in each of the years that a choice is observed for him in the data. ${ }^{12}$ Aggregate measures for the sample, which are created by averaging these individual-specific choice probabilities across all sample members, are shown in the first column of Table 9a. The first entries in Column 1 represent the choice probabilities that are generated if individual choices at all ages are pooled. ${ }^{13}$ Thus, under the baseline specification, our model indicates that individuals will choose the work option $(\mathrm{C}+\mathrm{B})$ in .859 of the periods for which decisions are observed in the data (hereafter referred to as the pooled decision periods), will choose the non-work option $(\mathrm{N})$ in .125 of the pooled decision periods, and will choose to apply for Disability Insurance (A) in .016 of the pooled decision periods. ${ }^{14}$ The remainder of the entries in Column 1 reflect the choice probabilities when choices are disaggregated by age (for select ages). Thus, for example, the simulations indicate that the probability of working $(\mathrm{C}+\mathrm{B})$ at age 55 is $.863 .{ }^{15}$

For each policy change, the simulation process is repeated after modifying the model appropriately to reflect the change. Column 2 of Table 9a shows the choice probabilities associated with a first policy change in which no benefits are available from the Social Security system until a person reaches the age of 65 . When a person is younger than 62, this policy change influences decisions only through its influence on future income. Because knowledge that Social Security benefits will not be available at the ages of 62-64 tends to reduce the value of each option in a somewhat similar fashion, it is perhaps not surprising that the policy change has little effect before the age of 62 . For example, at age 55, the probability of choosing the non-work option $(\mathrm{N})$ is .115 under the baseline simulation and .113 under the policy change. The policy change leads to an increase in work at the age of 62 when the amount of current period consumption that a person receives in the non-work and DI options is reduced relative to the baseline case; at age 62 the probability of choosing the non-work option falls by approximately $18 \%$ (from .147 under the baseline simulation to .121 under the policy change). A similar effect (.172 versus .150) is shown in the table for age 64. The policy change leads to little change in the number of DI

\footnotetext{
${ }^{12}$ Thus, we take the approach of simulating choices within the sample period.
}

${ }^{13}$ Thus, for these entries we are averaging choice probabilities of all behavioral sample members in all years that choices are observed. Recall that the youngest age at which any individual in the sample is observed making a choice is 51 and the oldest age at which any individual in the sample is observed making a choice is 66 . Each individual contributes to the aggregate measures at a subset of these ages.

${ }^{14}$ In the data, the empirical probabilities are $.838, .153$, and .018 respectively.

${ }^{15}$ Given our within-sample period simulation strategy, this number is computed using all people for which a choice is observed in the data at age 55 . 
applicants. Thus, the decrease in the probability of choosing $\mathrm{N}$ is accompanied by an increase of similar size in the probability of choosing C or B. At 65 when Social Security benefits become the same in the baseline simulation and policy change simulation, the number of people in the option $\mathrm{N}$ becomes more similar under the baseline and policy change (.192 VS. .184). ${ }^{16}$

We have also constructed (but do not show here) an analog to Table 9a for individuals with health that is one standard deviation or more below the average for the sample (hereafter referred to as "bad" health) and for individuals in our sample with health that is better than one standard deviation below the average for the sample (hereafter referred to as "good" health). ${ }^{17}$ Consistent with our representative person simulations, we find evidence that the effect of this policy change varies with a person's health. For example, for individuals in our sample with bad health, the policy causes the probability of choosing $\mathrm{N}$ at age 64 to fall by approximately .06 (from .263 under the baseline to .204 under policy 1 ) and the probability of applying for DI to fall by approximately .03 (from .083 to .054). For individuals in our sample with "good" health, the policy causes the probability of choosing $\mathrm{N}$ at age 64 to fall by approximately .02 (from .158 under the baseline to .138 under policy 1 ) and the probability of choosing A to fall by .002 (from .013 to .011). Thus, this policy has a differential impact by health status by changing the work status of people in bad health more than the work status of people in good health; the probability of $\mathrm{C}+\mathrm{B}$ at age 64 increases by .088 for individuals in bad health but by only .021 for individuals in good health).

Column 3 of Table 9 (Policy 2) shows the choice probabilities associated with a second policy which influences Social Security benefits in a less drastic way than the first policy. Specifically, the policy change involves increasing the normal retirement age from 65 to 67 . Under this policy, while individuals still become eligible for benefits at the age of 62 , the amount of the benefits that is received if one retires at age 62 or at any other age is reduced. ${ }^{18}$ This change in the normal retirement age is currently being phased in. A comparison of Column 1 and Column 3 of Table 9a reveals that this policy will have relatively small effects on individual decisions. The change has virtually no effect before age 62 . At ages 62 or

\footnotetext{
${ }^{16}$ The small difference remains because, under the policy change, individuals are less likely to have left their career jobs as of age 65, and, therefore, have an additional and often desirable work option at age 65.

${ }^{17}$ True health is not observed in our data. However, our model produces the distribution of health for a particular person. This can be used to compute the probability that a person is in "good" or "bad" health.

${ }^{18}$ Under this policy, a person who retires at the age of 67 receives the benefits he would have received under baseline if he would have retired at age 65. A similar reduction in benefits takes place at all other ages.
} 
higher, the policy causes a decrease in the probability of the non-work option $(\mathrm{N})$ of one percentage point or approximately seven percent for people in our sample.

Column 4 of Table 9a (Policy 3 ) shows the choice probabilities associated with a third policy change in which the Disability Insurance program is removed entirely. Comparing the entries associated with $\mathrm{C}+\mathrm{B}$ in Column 4 to the entries associated with $\mathrm{C}+\mathrm{B}$ in Column 1 reveals that the removal of the DI program leads to very little change in the proportion of people who are working at any particular age. Instead, the change leads primarily to an increase in the proportion of people who choose to leave the workforce altogether $(\mathrm{N})$. Intuitively this occurs because individuals are typically in bad health when they apply for DI benefits, and, as a result, tend to find the non-work option (N) relatively appealing when the DI option is not available. Analysis stratifying by health status shows that removing DI benefits has very little effect on individuals in good health. For individuals in poor health the removal of the DI option results in an increase in the probability of $\mathrm{N}$ but very little change in the probability of $\mathrm{C}+\mathrm{B} .{ }^{19}$ Thus, the differential impact of this policy change by health status comes not from a change in work status, but rather, from a reduction in the benefits associated with being out of the workforce that arises because the person does not receive income from DI benefits.

Column 5 of Table 9 shows the choice probabilities associated with a final policy change in which individuals are given access to medicare at all ages. We find that this change has very small effects both overall and for different health groups. Given the small effect that health insurance seems to have on out of pocket medical expenses and give the small direct effect it has on utility (at least for this group), this result is not at all surprising.

\section{Conclusion}

\footnotetext{
${ }^{19} \mathrm{As}$ in Table 9a for the entire sample, removing the DI option for the bad health individuals leads to a seemingly counterintuitive decrease in the probability associated with the working options $(\mathrm{C}+\mathrm{B})$. The reason for this is simply that the policy change has an effect on the number of pooled decision years for which choices are simulated. Consistent with what is seen in the data, the likelihood contribution for a person assumes that a person who applies for DI and is accepted makes no subsequent decisions (i.e., he remains on DI forever). Analogously, when constructing Table 9, subsequent choices are not simulated for a person who applies for and is accepted for DI benefits. Thus, removing the DI option leads to more simulated choices for the types of people who apply for and are awarded DI benefits. The decrease in the probability of C+B under the policy change occurs because these types of people tend to be in bad health,and find the option $\mathrm{N}$ relatively appealing. This can be formalized by recomputing the choice probabilities in Table 9 replacing the DI application category (A) with a new category (call it $\mathrm{A}^{*}$ ) which includes both people who are applying for DI in the present period and people who have been accepted in the past (and as a result are on DI in the current period but are not making decisions which enter the numbers in Table 9). In this case, for the entire sample the probability associated with $\mathrm{C}+\mathrm{B}$ is .840 under the baseline and .854 under policy 3 . The probability of $\mathrm{A}^{*}$ is .038 under the baseline and is zero by definition under policy 3 . For individuals in bad health, the probability associated with $\mathrm{C}+\mathrm{B}$ is .712 under the baseline and .743 under policy 3 . The probability of $\mathrm{A}^{*}$ is .111 under the baseline and is zero by definition under policy 3 . Thus, the probability of $\mathrm{C}+\mathrm{B}$ increases as expected when the DI is removed. In addition, note that for individuals in bad health, the increase in the probability of $\mathrm{C}+\mathrm{B}(.032)$ is relatively small compared to the number of people who are forced to leave DI under the policy (i.e., .111) so that the removal of the DI option leads primarily to an increase in the proportion of people that are in the option $\mathrm{N}$.
} 
In this paper, we report estimates of a dynamic programming model that addresses the interplay among health, financial resources, and the labor market behavior of men nearing retirement age. Our simulations indicate that both health and economic resources play an important role in determining labor supply decisions of older workers. Our estimates imply that individuals in good health are unlikely to retire unless they have generous financial resources available to them. On the other hand, our estimates imply that a man in poor health is quite likely to leave the workforce even when he is not yet eligible for any kind of pension benefits. In fact, simulations based on our model estimates show that our representative individual in poor health is 10 times more likely than a similar person in average health to retire before becoming eligible for pension benefits. These estimates underline the importance that health plays in determining early retirement behavior.

Strikingly our estimates imply that changes in the Social Security Retirement Program are likely to have minimal effects on applications for the Disability Insurance Program. ${ }^{20}$ We suspect that the reason for this has to do with the fact that those potentially eligible for DI are a quite a distinct population. Our findings have strong predictions about the patterns of the application for DI benefits we should see observe as the age for normal retirement under Social Security rises over the next decade. Despite the fact that this change will substantially increase the financial rewards associated with receiving DI rather than early retirement benefits, our estimates suggest that the number of individuals over the age of 62 apply for DI will not rise by much.

${ }^{20} \mathrm{As}$ far as we know the only other attempt to estimate the impact of changes in the Social Security Retirement Program on Disability participation is the work by Mitchell and Phillips (2000). Mitchell and Phillips use a conditional logit framework to study the effect of financial incentives on the probability that a person will retire early or apply for disability insurance. Their estimates imply a larger effect on the application for DI benefits of reducing the incentives to retire early. The modeling approach we take is so different than the one taken by Mitchell and Phillips that it is hard to know what to attribute differences to. 


\section{Table 4 Descriptive Statistics}

\begin{tabular}{|c|c|c|c|c|c|c|}
\hline & \multirow[b]{2}{*}{$\begin{array}{r}\text { Working at } \\
\mathbf{t}=\mathbf{0}\end{array}$} & \multirow[b]{2}{*}{$\begin{array}{r}\text { Not working } \\
\text { at } t=0\end{array}$} & \multicolumn{4}{|c|}{ Of those working at $\mathrm{t}=\mathbf{0}$, behavior last obs ervation } \\
\hline & & & Career & Bridge & Retired & Dis ability \\
\hline Age at wave 4 & 60.6 & 61.1 & 59.8 & 61.1 & 62.0 & 59.6 \\
\hline$<$ High School & 0.222 & 0.261 & 0.243 & 0.229 & 0.188 & 0.267 \\
\hline Some College & 0.170 & 0.183 & 0.135 & 0.114 & 0.208 & 0.333 \\
\hline College Grad & 0.193 & 0.191 & 0.243 & 0.114 & 0.167 & 0.200 \\
\hline Work limited at wave 1 & 0.097 & 0.296 & 0.095 & 0.143 & 0.083 & 0.067 \\
\hline Work limited at wave 4 & 0.188 & 0.365 & 0.108 & 0.057 & 0.208 & 0.867 \\
\hline Age 62 or older at wave 4 & 0.369 & 0.435 & 0.243 & 0.457 & 0.583 & 0.133 \\
\hline $\begin{array}{l}\text { Normal retirement benefit (assuming } \\
\text { no further work) }\end{array}$ & 12,820 & 11,271 & 13,136 & 12,327 & 12,775 & 11,711 \\
\hline Eligible for DB pension ever & 0.466 & 0.078 & 0.419 & 0.486 & 0.542 & 0.333 \\
\hline Eligible for DC pension ever & 0.369 & 0.122 & 0.405 & 0.371 & 0.375 & 0.267 \\
\hline Expected Career Earnings at last obs & 32,854 & 6,048 & 33,143 & 32,904 & 34,700 & 23,761 \\
\hline Expected Bridge Earnings at last obs & 13,098 & 2,294 & 14,647 & 12,253 & 10,658 & 13,793 \\
\hline With no employer health ins & 0.176 & & 0.095 & 0.314 & 0.125 & 0.467 \\
\hline With only current coverage & 0.290 & & 0.297 & 0.286 & 0.292 & 0.200 \\
\hline With both current \& retiree covg & 0.534 & & 0.608 & 0.400 & 0.583 & 0.333 \\
\hline Median Non-housing wealth & 18,900 & 15,000 & 20,250 & 15,000 & 24,000 & 8,000 \\
\hline Median Housing wealth & 4,750 & 0 & 250 & 0 & 33,500 & 10,000 \\
\hline Fraction Choosing & 0.605 & 0.395 & 0.430 & 0.204 & 0.279 & 0.087 \\
\hline
\end{tabular}

Table 5D Parameter Estimates

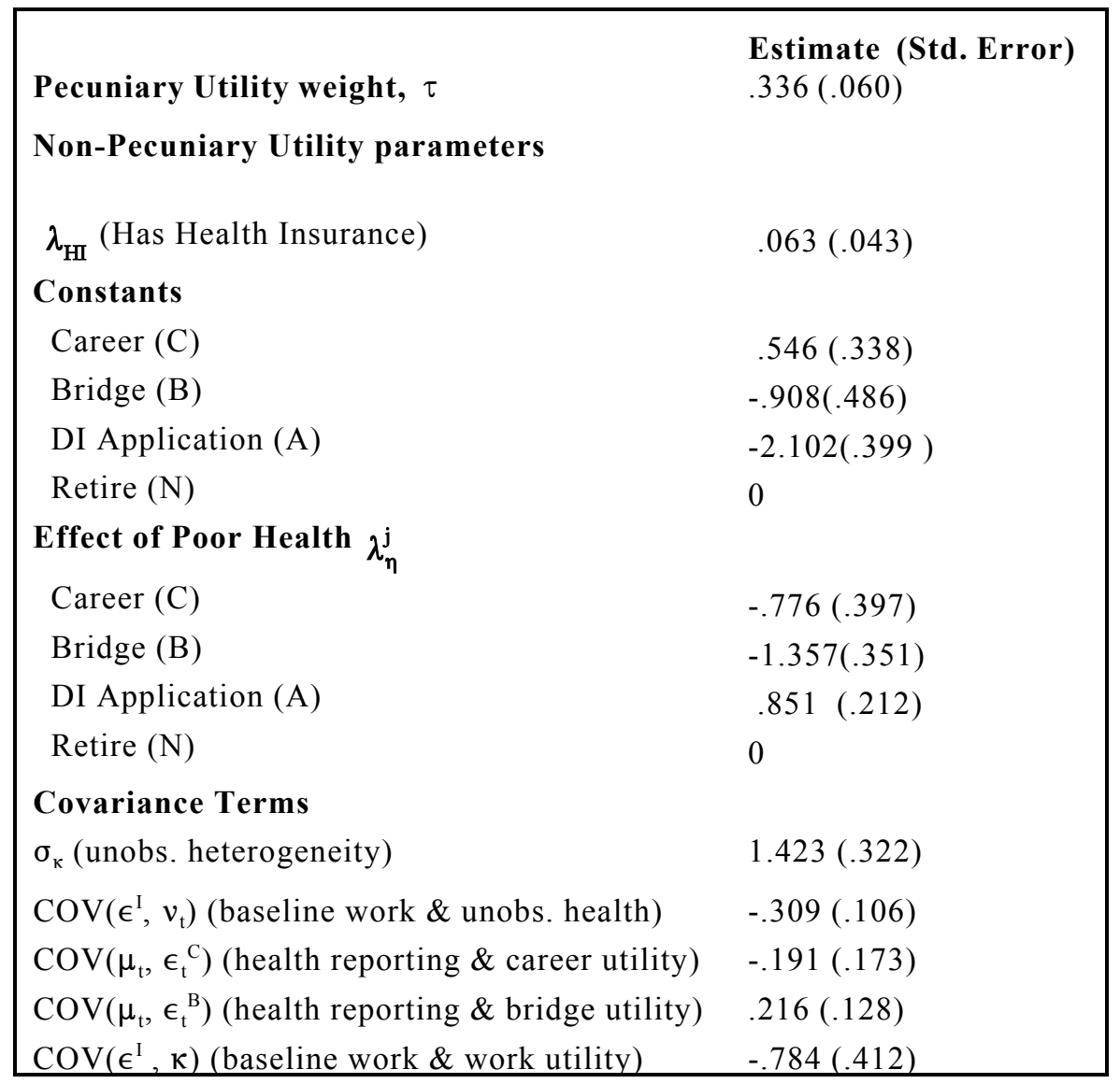

Table 6A Choice Probabilities Representative Person at Different Ages - Average Health Baseline Specification 


\begin{tabular}{|c|c|c|c|c|}
\hline & $\underline{\text { Working }(\mathrm{C}+\mathrm{B})}$ & $\underline{\text { Labor Force Exit }(\mathrm{N}+\mathbf{A})}$ & $\underline{\text { Non-Work }(\mathbf{N})}$ & $\underline{\text { Apply DI (A) }}$ \\
\hline $\mathrm{AGE}=55$ & 0.981 & 0.019 & 0.018 & 0.001 \\
\hline$A G E=60$ & 0.974 & 0.025 & 0.024 & 0.001 \\
\hline $\mathrm{AGE}=62$ & 0.951 & 0.049 & 0.046 & 0.003 \\
\hline $\mathrm{AGE}=64$ & 0.947 & 0.053 & 0.050 & .003 \\
\hline$A G E=65$ & 0.947 & 0.053 & 0.0533 & $\mathrm{NA}^{*}$ \\
\hline
\end{tabular}

* person cannot apply for Disability Insurance at age 65 or older.

Table 6B Choice Probabilities Representative Person at Different Ages - Health 1 Std. Dev. Below Average Baseline Specification

\begin{tabular}{|c|c|c|c|c|}
\hline & $\underline{\text { Working }(\mathrm{C}+\mathrm{B})}$ & $\underline{\text { Labor Force Exit }(\mathbf{N}+\mathbf{A})}$ & $\underline{\text { Non-Work }(\mathbf{N})}$ & Apply DI (A) \\
\hline $\mathbf{A G E}=55$ & 0.902 & 0.098 & 0.057 & 0.041 \\
\hline$A G E=60$ & 0.893 & 0.106 & 0.082 & 0.024 \\
\hline $\mathrm{AGE}=62$ & 0.831 & 0.168 & 0.138 & 0.030 \\
\hline $\mathrm{AGE}=64$ & 0.828 & 0.172 & 0.146 & 0.026 \\
\hline$A G E=65$ & 0.839 & 0.161 & 0.161 & $\mathrm{NA}^{*}$ \\
\hline
\end{tabular}

* person cannot apply for Disability Insurance at age 65 or older.

Table 6C Choice Probabilities Representative Person at Different Ages - Health 1.5 Std. Dev. Below Average

Baseline Specification

\begin{tabular}{|c|c|c|c|c|}
\hline & $\underline{\text { Working }(\mathrm{C}+\mathrm{B})}$ & $\underline{\text { Labor Force Exit }(\mathbf{N}+\mathbf{A})}$ & $\underline{\text { Non-Work }(\mathbf{N})}$ & Apply DI (A) \\
\hline $\mathbf{A G E}=55$ & 0.805 & 0.195 & 0.084 & 0.111 \\
\hline$A G E=60$ & 0.802 & 0.198 & 0.127 & 0.071 \\
\hline$A G E=62$ & 0.731 & 0.269 & 0.209 & 0.060 \\
\hline AGE $=64$ & 0.721 & 0.279 & 0.207 & 0.072 \\
\hline $\mathrm{AGE}=65$ & 0.745 & 0.254 & 0.254 & NA* \\
\hline
\end{tabular}

* person cannot apply for Disability Insurance at age 65 or older. 
Table 9a Policy Simulations - All Health Combined

\begin{tabular}{|c|c|c|c|c|c|}
\hline & Baseline & Policy 1 & Policy 2 & Policy 3 & Policy 4 \\
\hline \multirow[t]{4}{*}{ Pooled Ages } & $\mathrm{C}+\mathrm{B}=.859$ & $\mathrm{C}+\mathrm{B}=.866$ & $\mathrm{C}+\mathrm{B}=.862$ & $\mathrm{C}+\mathrm{B}=.854$ & $\mathrm{C}+\mathrm{B}=.860$ \\
\hline & $\mathrm{N}+\mathrm{A}=.141$ & $\mathrm{~N}+\mathrm{A}=.134$ & $\mathrm{~N}+\mathrm{A}=.138$ & $\mathrm{~N}+\mathrm{A}=.146$ & $\mathrm{~N}+\mathrm{A}=.140$ \\
\hline & $\mathrm{N}=.125$ & $\mathrm{~N}=.117$ & $\mathrm{~N}=.121$ & $\mathrm{~N}=.146$ & $\mathrm{~N}=.125$ \\
\hline & $A=.016$ & $\mathrm{~A}=.017$ & $\mathrm{~A}=.017$ & $\mathrm{~A}=.000 * *$ & $\mathrm{~A}=.015$ \\
\hline \multirow[t]{4}{*}{$A G E=55$} & $\mathrm{C}+\mathrm{B}=.863$ & $\mathrm{C}+\mathrm{B}=.865$ & $\mathrm{C}+\mathrm{B}=.864$ & $\mathrm{C}+\mathrm{B}=.862$ & $\mathrm{C}+\mathrm{B}=.863$ \\
\hline & $\mathrm{N}+\mathrm{A}=.137$ & $\mathrm{~N}+\mathrm{A}=.135$ & $\mathrm{~N}+\mathrm{A}=.136$ & $\mathrm{~N}+\mathrm{A}=.138$ & $\mathrm{~N}+\mathrm{A}=.133$ \\
\hline & $\mathrm{N}=.115$ & $\mathrm{~N}=.113$ & $\mathrm{~N}=.114$ & $\mathrm{~N}=.138$ & $\mathrm{~N}=.112$ \\
\hline & $\mathrm{A}=.022$ & $\mathrm{~A}=.023$ & $\mathrm{~A}=.022$ & $\mathrm{~A}=0.000 * *$ & $\mathrm{~A}=.021$ \\
\hline \multirow[t]{4}{*}{$A G E=60$} & $\mathrm{C}+\mathrm{B}=.858$ & $\mathrm{C}+\mathrm{B}=.862$ & $\mathrm{C}+\mathrm{B}=.860$ & $\mathrm{C}+\mathrm{B}=.852$ & $\mathrm{C}+\mathrm{B}=.857$ \\
\hline & $\mathrm{N}+\mathrm{A}=.141$ & $\mathrm{~N}+\mathrm{A}=.138$ & $\mathrm{~N}+\mathrm{A}=.140$ & $\mathrm{~N}+\mathrm{A}=.148$ & $\mathrm{~N}+\mathrm{A}=.143$ \\
\hline & $\mathrm{N}=.131$ & $\mathrm{~N}=.125$ & $\mathrm{~N}=.128$ & $\mathrm{~N}=.148$ & $\mathrm{~N}=.133$ \\
\hline & $\mathrm{A}=.010$ & $\mathrm{~A}=.013$ & $\mathrm{~A}=.011$ & $\mathrm{~A}=.000 * *$ & $\mathrm{~A}=.010$ \\
\hline \multirow[t]{4}{*}{$\mathrm{AGE}=62$} & $\mathrm{C}+\mathrm{B}=.840$ & $\mathrm{C}+\mathrm{B}=.866$ & $\mathrm{C}+\mathrm{B}=.849$ & $\mathrm{C}+\mathrm{B}=.837$ & $\mathrm{C}+\mathrm{B}=.839$ \\
\hline & $\mathrm{N}+\mathrm{A}=.160$ & $\mathrm{~N}+\mathrm{A}=.134$ & $\mathrm{~N}+\mathrm{A}=.151$ & $\mathrm{~N}+\mathrm{A}=.163$ & $\mathrm{~N}+\mathrm{A}=.161$ \\
\hline & $\mathrm{N}=.147$ & $\mathrm{~N}=.121$ & $\mathrm{~N}=.137$ & $\mathrm{~N}=.163$ & $\mathrm{~N}=.148$ \\
\hline & $\mathrm{A}=.013$ & $\mathrm{~A}=.013$ & $\mathrm{~A}=.015$ & $\mathrm{~A}=.000 * *$ & $\mathrm{~A}=.013$ \\
\hline \multirow[t]{4}{*}{$\mathrm{AGE}=64$} & $\mathrm{C}+\mathrm{B}=.806$ & $\mathrm{C}+\mathrm{B}=.831$ & $\mathrm{C}+\mathrm{B}=.815$ & $\mathrm{C}+\mathrm{B}=.795$ & $\mathrm{C}+\mathrm{B}=.804$ \\
\hline & $\mathrm{N}+\mathrm{A}=.195$ & $\mathrm{~N}+\mathrm{A}=.169$ & $\mathrm{~N}+\mathrm{A}=.185$ & $\mathrm{~N}+\mathrm{A}=.205$ & $\mathrm{~N}+\mathrm{A}=.196$ \\
\hline & $\mathrm{N}=.172$ & $\mathrm{~N}=.150$ & $\mathrm{~N}=.160$ & $\mathrm{~N}=.205$ & $\mathrm{~N}=.173$ \\
\hline & $\mathrm{A}=.023$ & $\mathrm{~A}=.019$ & $\mathrm{~A}=.024$ & $\mathrm{~A}=.000 * *$ & $\mathrm{~A}=.023$ \\
\hline \multirow[t]{4}{*}{$\mathrm{AGE}=65$} & $\mathrm{C}+\mathrm{B}=.808$ & $\mathrm{C}+\mathrm{B}=.816$ & $\mathrm{C}+\mathrm{B}=.820$ & $\mathrm{C}+\mathrm{B}=.782$ & $\mathrm{C}+\mathrm{B}=.807$ \\
\hline & $\mathrm{N}+\mathrm{A}=.192$ & $\mathrm{~N}+\mathrm{A}=.184$ & $\mathrm{~N}+\mathrm{A}=.180$ & $\mathrm{~N}+\mathrm{A}=.218$ & $\mathrm{~N}+\mathrm{A}=.193$ \\
\hline & $\mathrm{N}=.192$ & $\mathrm{~N}=.184$ & $\mathrm{~N}=.180$ & $\mathrm{~N}=.218$ & $\mathrm{~N}=.193$ \\
\hline & $\mathrm{A}=.000 *$ & $\mathrm{~A}=.000 *$ & $\mathrm{~A}=.000 *$ & $\mathrm{~A}=.000 *$ & $\mathrm{~A}=.000 *$ \\
\hline
\end{tabular}

* person cannot apply for Disability Insurance at age 65 or older.

** policy involves removing Disability Insurance program.

Policy 1 involves removing all SS benefits before age 65 .

Policy 2 involves changing the normal retirement age from 65 to 67 .

Policy 3 involves removing the DI program.

Policy 4 involves giving individuals medicare in all periods, regardless of age. 


\section{References}

Bellman, R. (1957): Dynamic Programming. New Jersey: Princeton University Press.

Benitez-Silva, Hugo, Moshe Buchinsky, Hiu Man Chan, Sofia Cheidvasser and John Rust, (2000): “How Large is the Bias is Self-Reported Disability?" NBER Working Paper \# 7526.

Benitez-Silva, Hugo, Moshe Buchinsky, and John Rust, (2004): "How Large Are the Classification Errors in the Social Security Disability Award Process?” NBER Working Paper \# 10219.

Berkovec, J., and S. Stern (1991): "Job Exit Behavior of Older Men," Econometrica, 59(1), 189-210.

Blau, D. and D. Gilleskie (2001): "Health Insurance and Retirement of Married Couples," unpublished manuscript, Department of Economics, the University of North Caroline.

Bound, J. (1991): "Self-reported Versus Objective Measures of Health in Retirement Models," The Journal of Human Resources, 26, 106-138.

Bound, John, Michael Schoenbaum, Todd Stinebrickner, and Timothy Waidmann (1998): "Modeling the Effect of Health on Retirement Behavior," paper presented at the National Bureau of Economics Summer Institute.

Bound, John, Michael Schoenbaum, Todd Stinebrickner, and Timothy Waidmann (1999): "The Dynamic Effects of Health on the Labor Force Transitions of Older Workers," Labour Economics, 6(2), 179-202.

Bound, J., and T. Waidmann (2002): “Accounting for Recent Declines in Employment Rates among Working-Aged Men and Women with Disabilities," Journal-of-Human-Resources; 37(2), Spring 2002, pages 231-50.

Burkhauser, R.V., D Dwyer, M. Lindeboom, J. Theeuwes, I. Woittiez (1999): “Health, Work, and Economic Well-Being of Older Workers, Aged Fifty-One to Sixty-One: A Cross-National Comparison Using the U.S. HRS and the Netherlands CERRA Data Sets," Smith,J. P and R. J. Willis, eds. Wealth, work, and health: Innovations in measurement in the social sciences: Essays in honor of F. Thomas Juster. Ann Arbor: University of Michigan Press, pages 233-66.

French, Eric (2000): “The Effects Of Health, Wealth, And Wages On Labor Supply And Retirement Behavior," Federal Reserve Bank of Chicago working paper \# 2000-02.

French, Eric and John Bailey Jones (2001): “The Effects of Health Insurance and Self-Insurance on Retirement Behavior," Federal Reserve Bank of Chicago working paper \# 2000-19.

Juster, F. T., and R. Suzman (1995): "An Overview of the Health and Retirement Study," Journal of Human Resources, 30(0), Suppl., S7-56.

Kreider, Brent (1999): "Latent Work Disability and Reporting Bias," Journal of Human Resources; 34, 734-69

Mitchell Olivia and John W.R. Phillips (2000): "Retirement Responses to Early Social Security Benefit Reductions," NBER Working Paper 7963, National Bureau of Economic Research, Inc.

Quinn, J.F., and M. Kozy (1995): “Bridge Jobs in the 1990s,” Presented at the HRS Wave 2 Early Results Workshop, Ann Arbor, October.

Rust, J., and C. Phelan (1997): "How Social Security and Medicare Affect Retirement Behavior in a World of Incomplete Markets," Econometrica, 65(4), 781-831.

Rust, John, Moshe Buchinsky and Hugo Benitez-Silva (2001): “An Empirical Model of Social Insurance at the End of the Life Cycle." ftp://gemini.econ.umd.edu/pub/johnrust/disability/nsfpro.pdf.

Stern, Steven (1989): "Measuring the Effect of Disability on Labor Force Participation," The Journal of Human Resources, Vol. 24, 361-395

van der Klaauw, Wilbert, and Kenneth I. Wolpin (2002): "Social Security, Pensions and the Savings and Retirement Behavior of Households," Unpublished Manuscript, Department of Economics, University of North Carolina.

Waidmann, T, J Bound, and M Schoenbaum (1995): "The Illusion of Failure: Trends in Self-reported Health of the U.S. Elderly." The Milbank Quarterly, 73, No. 2: 253-87. 